\title{
The use of total-body counters for the study of iron metabolism and iron loss
}

\author{
G. T. WARNER \\ D.Phil.
}

\author{
Nuffield Department of Clinical Medicine, The Radcliffe Infirmary, Oxford $O X 26 H E$
}

\begin{abstract}
Summary
Total-body counters designed for clinical use have considerable advantage and application over other methods for the measurement of iron metabolism. An investigation may be performed on an out-patient basis and the need for faecal collections avoided.

Although the initial cost of their installation is high, this can be off-set by the saving of in-patient costs in 2 or 3 years of operation.
\end{abstract}

\section{Introduction}

Radioisotopes of iron have been of considerable importance in the study of iron metabolism for some 20 years. The technique has almost completely supplanted the chemical iron balance study which, with all the problems associated with the measurement of small quantities of iron in biological specimens, was the only method available to the research worker in this field.

The radioisotope techniques allow for a direct measurement of iron absorption, plasma iron turnover, red cell utilization, and the localization of iron by surface counting techniques. Of these, the measurement of iron absorption and iron loss are of the most practical importance.

During the period which radioisotopes of iron have been generally available, a great deal of effort has been applied to the design and construction of various forms of counting apparatus and to the experimental techniques themselves. The effort directed towards the provision of counting apparatus has culminated in the present range of designs of total-body counters for clinical applications.

The basic principle of any measurement using a tracer technique is quite simple. A dose of labelled substance is administered to the patient, the number of radioactive disintegrations or 'counts' in unit time are assessed and, at some later time the number of 'counts' excreted or appearing in blood or retained in the body are assessed.

\section{Radioisotopes of iron}

Of the radioisotopes of iron available, ${ }^{59} \mathrm{Fe}$ is the nuclide most frequently used because the half-life of 44.5 days is convenient, and because it emits both medium energy beta particles and gamma radiation, therefore conventional counting methods can be used including total-body counting of the gamma emission. ${ }^{55} \mathrm{Fe}$, whilst having a half-life that permits long-term studies of iron metabolism, is the most difficult to detect as it decays by $\mathrm{K}$-capture and yields only X-ray emission of some $6 \mathrm{keV}$. Methods of measurement have been developed using either an argon-filled thin end-window Geiger-Müller (GM) tube (Peacock et al., 1946) or a gas flow counter (Hallberg \& Brise, 1960), or a liquid scintillation counting technique (Dern \& Hart, 1961; Jenner \& Öbrink, 1962; Perry \& Warner, 1963; Eakins \& Brown, 1965). Total-body counting of this isotope is not possible.

The very different characteristic emission of ${ }^{59} \mathrm{Fe}$ and ${ }^{55} \mathrm{Fe}$ makes possible a double labelling technique whereby a simultaneous administration of, for instance, two different forms of elemental iron is possible. The two isotopes may be separately determined on a common counting system (Hallberg, Sölvell \& Brise, 1958) or by using separate counting systems whereby the ${ }^{55} \mathrm{Fe}$ is counted by one of the methods described and the ${ }^{59} \mathrm{Fe}$ by total-body counting (Hallberg \& Björn-Rasmussen, 1972).

The very short half-life and limited availability of ${ }^{52} \mathrm{Fe}\left(\mathrm{t} \frac{1}{2}=8.3 \mathrm{hr}\right)$ limits its application to studies of short duration (Francois \& Szur, 1958).

\section{Methods of measurement}

In one of the earlier studies (Haln et al., 1939) the proportion of an oral dose of labelled iron appearing in the red cells was taken as a measure of iron absorption. For the normal subject some $70 \%$ of that absorbed from an oral dose of an inorganic salt is utilized for haemoglobin production. In simple iron deficiency, almost all of that absorbed is incorporated into new red cells within a few days following an oral dose. Therefore, in this situation the measurement of the amount of radioactive iron appearing in the red cells can be taken as a reasonable indication of the total absorption. For the normal subject the method gives only an approximation and always an underestimation. In more complicated anaemia a greater proportion of the absorbed dose may be stored and the figures for red cell utilization may be very different from those for absorption (Callender, 1962). 
The use, therefore, of this method of estimation of iron absorption is clearly only applicable to certain groups of subjects. Because of this Dubach, Callender \& Moore (1948) introduced measurement in the faeces of the unabsorbed portion of the dose which, if the faecal collection is complete, gives a better indication of iron absorption. The red cell utilization may also be determined on the same subject as an independent parameter.

The method of measurement of the ${ }^{59} \mathrm{Fe}$ in these early studies was by beta counting. A wet digestion technique of the blood or faecal sample was followed by electroplating of the iron on to copper discs (Dubach et al., 1948). An improvement in the counting technique was the substitution of a sodium iodide (TL) scintillation counter for the GM beta counter (Oliver, 1953). A sample of blood or homogenized faeces could then be counted without any prior chemical operations. Homogenization of faecal samples was necessary to ensure an even distribution of the activity within the sample (Badenoch \& Callender, 1954).

Booth \& Mollin (1956) described an arrangement of thirty-two small GM tubes arranged in a ring configuration which, using the gamma emission of ${ }^{50} \mathrm{Fe}$, had a geometry which allowed a faecal sample of up to $500 \mathrm{~g}$ to be counted without prior homogenization.

Large volume well scintillation counters using a plastic scintillator have also been described (Warner \& Oliver, 1962; Cook \& Valberg, 1963; Paix, Davis \& Blagonravoff, 1965). Clapham \& Hayter (1962) have used two horizontally opposed NaI (TL) detectors. These counters also have a response characteristic that is essentially independent of the distribution of the activity within the sample and have the advantage of a higher sensitivity than the GM ring counter.

Although these apparatus considerably improved the counting procedure, the problems associated with faecal collection remain. A method therefore, which obviates the need for such collection and where a measurement of the retained portion of the dose is obtained rather than a measurement of the excreted portion, would have considerable advantage and allow the tests to be performed on a wider range of clinical subjects. Such measurements of the radioactivity in the whole subject can be performed by a total-body counter.

Currently, therefore, the counting method of choice is the total-body counter.

\section{Total-body counters}

Total-body counters were first developed by Health Physics groups for the measurement of fallout and contamination levels in radiation workers, the principal requirement being a high sensitivity rather than a response independent of the distribu气 tion of the radioactivity in the body. Large volume detectors such as NaI (TL) crystals (Rundo, 1958 Miller, 1962), plastic scintillators (Burch \& Spiers, 1953) or large tanks of liquid scintillator (Andersor et al., 1956; Christian, Kessler \& Ziemer, 1962) were $e^{+}$ used and, to reduce the background count to ato acceptable level, both the patient and the detectors: were contained in a lead or steel room (Fig. 1) Several workers have applied these counters for iror? metabolism investigations (Price et al., 1962; Saitø et al., 1964) but, in general, the high initial cost and weight was a limiting factor for their more general use. However, for clinical measurements, the require $\vec{\epsilon}$ ments are not so stringent, since doses of severas microcuries can usually be administered for diag? nostic investigations; the shielding against back ground radiation can therefore be reduced. Chalkş for example, has been used for the walls of the counting room (Trott et al., 1963; Tappin, 1963) In another design, a minimum of shielding has been used, with only the sides and top of the detector shielded (Glass, Clarkson \& Burns, 1964; Pirche? et al., 1965).

A fresh approach has been to provide only partiaf shielding of lead or steel, so arranged that no direct. background radiation can reach the detector without first passing through the shield. Background rade tion entering through the open sides of the shieflo must be deflected through at least $90^{\circ}$ before it ẹan reach the detector, thus losing energy. This scatteres radiation is then always below an energy level of $0.51 \mathrm{MeV}$ (Compton, 1923). It follows that if $\mathrm{NaB}$ (TL) detectors are used which have the inheren ability to produce an output which is proportiona? to the energy of the incident radiation, it is possible, by pulse height discrimination techniques, to reject

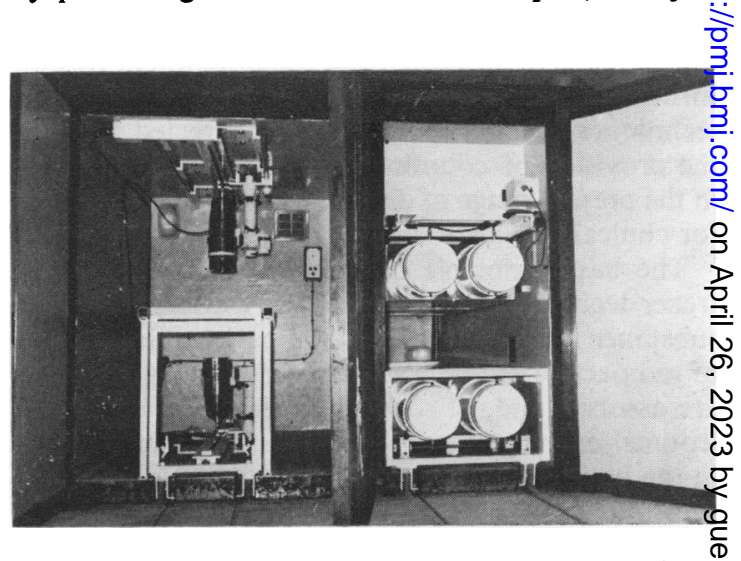

Fig. 1. A fully shielded room total-body counter with two separate compartments. The detectors in the lefthand section are sodium iodide crystals and in the righthand section, large plastic phosphors in a $3 \pi$ configuration (Nuclear Enterprises Ltd.).

.


those events below $0.51 \mathrm{MeV}$. Thus, although only limited shielding is used the background count above this energy level approximates to that for a fully shielded room (Fig. 2).

This design of shield, which is called the "shadow shield technique', has been used by many workers to overcome the cost and weight problem of the fully shielded room (Lindel, 1962; Roesch \& Palmer, 1963; Warner \& Oliver, 1966; Boddy, 1967; Dudley, 1970 ). The weight of a typical shadow shield totalbody counter is in the range 4-12 tons against 40-60 tons for the fully shielded room.

An important requirement for clinical use, is that the total observed count must be independent of changes in distribution of the isotope within the patient if results are to be determined without lengthy calibration procedures. In physical terms, the counter must have a high degree of spatial uniformity of response. Various methods have been employed to achieve this end result (Oliver \& Warner, 1966; Barnaby \& Smith, 1971), in general most workers using ${ }^{59} \mathrm{Fe}$ count either a contribution of the Compton continuum with the photopeak or the Compton continuum alone (Palmer et al., 1970; Cook et al., 1970).

Where vertically opposed detectors are used, the taking of a geometric mean of the counts from the two detectors has been shown to produce good results even when the photopeak alone is counted (Tothill \& Galt, 1971).

In a combined study of faecal excretion and totalbody retention, Warner \& Oliver (1966) obtained a ratio of $1.012 \pm 0.12$ between the two methods, the standard deviation being reduced to \pm 0.075 (average ratio 1.00 ) by excluding six cases where the totalbody measurement was carried out in the presence

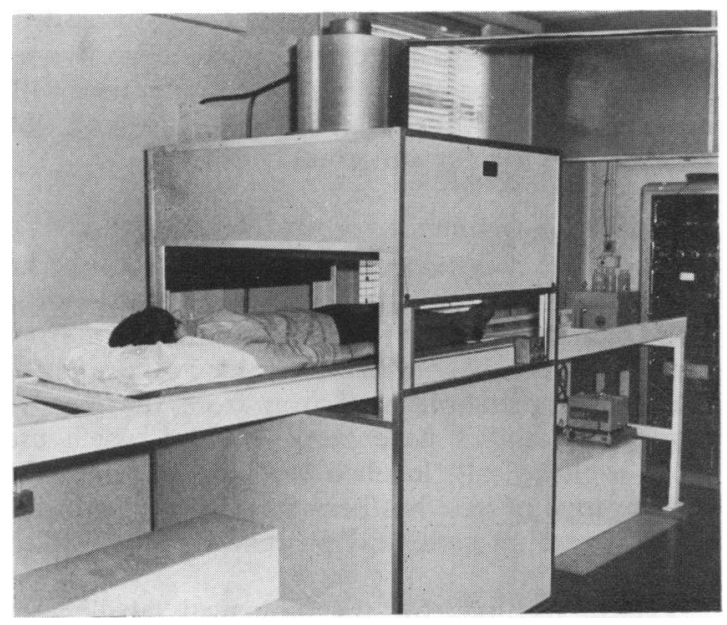

Fig. 2. A shadow shield total-body counter designed for clinical use (Radcliffe Infirmary, Oxford). of a high residual activity from a previous tracer test, with a consequent poorer statistical accuracy in the determination.

\section{The precision of measurement}

The variability of the value of absorption for any subject is comprised of two major components. Firstly, the statistical accuracy for the actual counting process and secondly, that variation attributable to the biological function being measured. For the statistical variation, the precision can be estimated from a knowledge of the observed counts that comprise the retention calculation. Because this calculation is made up of a number of observations each with a Poisson distribution, simple statistical criteria such as that proposed by Loevinger \& Berman (1951) cannot be applied. For this situation a method of estimating the standard error of the retention estimate has been given (Anderson \& Warner, 1970) using the Delta technique of Kendall \& Stuart (1958). This technique provides an approximate solution to the finding of the standard error of a function of random variables. The value obtained for this standard error is dependent upon the sensitivity of the counter, the background count-rate, the counting time and on the quantity of radioactivity given for a particular test.

In terms of sensitivity and background, large diameter (8-12 in) detectors in a shadow shield configuration provide, in the energy range above $0.51 \mathrm{MeV}$, a comparable performance to the fully shielded room. The highest sensitivity of all, however, is provided by the $4 \pi$ liquid scintillation counter which can only be housed in a fully shielded room. Heinrich (1970) has shown that with a counter of this design the very high sensitivity obtained makes it possible not only to perform absorption tests with a much reduced dose of radioactivity, but also to extend to a year the period over which meaningful measurements of iron loss may be made.

In designing a test procedure the relative importance of counter sensitivity, background, counting time, and more importantly the quantity of radioactive material administered for a particular test, should be viewed in the light of the clinical assessment of the result of the test, that is in the light of the largest acceptable standard error of the absorption estimate. This is particularly relevant as it is often the second major component, the biological variation, that provides the major source of variability.

In circumstances where the greatest precision is required, for instance where small differences in absorption are being measured and it is these differences that are themselves important, a technique is available which reduces the effects due to biological variation by producing an effective mean value for 
absorption from several administered doses given over a short period of time (Callender \& Warner, 1968). This multiple dose technique has been applied for the measurement of absorption of various forms of therapeutic iron (Callender \& Warner, 1971) and for the absorption of iron from various labelled foods (Callender, Marney \& Warner, 1970; Callender \& Warner, 1970).

The regime employed is to give a dose on each of 2 or more successive days; each dose containing the same quantity of elemental iron. The patient is counted before and after each dose to obtain the count corresponding to that particular dose. At some later time, usually 10-14 days after the last dose, the activity retained from all of the doses is measured. In general, 3 or 4 days of dosing are required if the method is to be used to advantage. The amount of radioactivity given is of course graded so that the total dose is of the same order as that given for a single test. This is possible because it is the observed count on day 14 that provides one of the principal components for the standard error of the absorption estimate.

\section{Iron absorption}

The amount of elemental iron given by various workers in an oral dose as a simple iron salt has ranged from 0.05 to $1.0 \mathrm{mg} / \mathrm{kg}$ of body weight (Josephs, 1958). The percentage absorption from a small dose of iron is greater than that absorbed from a larger dose. A relationship between the percentage

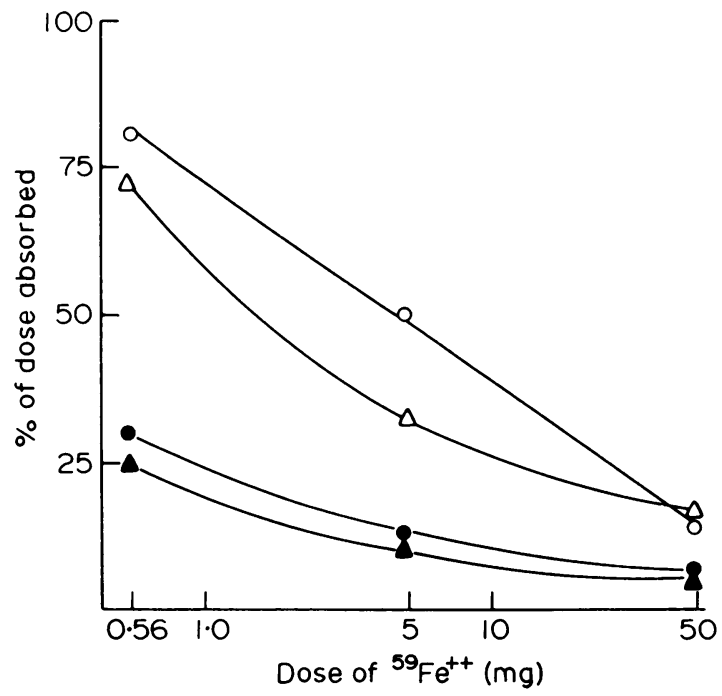

Fig. 3. The relationship between the percentage absorption and the dose in $\mathrm{mg}$ of $\mathrm{Fe}^{++}$(from Heinrich, 1970). $\mathrm{O}$, females, iron deficiency; -—, females, normal iron stores; $\Delta-\Delta$, males, iron deficiency; $\Delta-\Delta$, males, normal iron stores. absorption and the dose in $\mathrm{mg}$ of iron as $\mathrm{Fe}^{++}$has气 been derived by Heinrich (1970). These relationships show a difference between male and female subjects, 0 and between normal and depleted iron stores (Fig. 3) $:$ An acceptable level of dose for diagnostic investiga $\overrightarrow{\bar{c}}$ tions contains $5 \mathrm{mg}$ of elemental iron as ferrous sulphate, with $50 \mathrm{mg}$ of ascorbic acid and 1-3 $\mu \mathrm{C}$ of ${ }^{59} \mathrm{Fe}$. The ascorbic acid is added to keep the iron in a reduced form, thus providing optimal conditionso for absorption (Smith \& Mallett, 1957).

For diagnostic use the patient is usually starvedis for $4 \mathrm{hr}$ before and $2 \mathrm{hr}$ after the test, a background $\overrightarrow{0}$ count is taken and, following the oral dose, the patientis again counted to obtain the $100 \%$ level. The timing $\vec{\omega}$ of the count equivalent to $100 \%$ of the dose is usuallyo immediately following dosing (Callender et al. 1966), but some workers have found it necessary to delay counting for some hours to allow a more evence distribution of the iron within the body (Schiffer et al., 1964; Dymock, Godfrey \& Williams, 1971) This is usually necessary if the characteristics of the counter are such that large differences in count rateo are observed with the redistribution of the radio-? activity within the body.

At 10-14 days following the oral dose the patiente is again counted to determine the retained activity, a correction being made for radioactive decay. $\delta$

The percentage of the dose absorbed is related ${ }^{\circ}$ the state of the patient's iron stores and is grea increased in iron deficiency. A common clinie situation is that of a patient with iron deficiency whoo appears refractory to iron treatment. A test of irono absorption will distinguish between those who have@ true malabsorption of iron and others in whom an $\vec{\delta}$ explanation may be unsuspected continuous blood $\exists$ loss, or failure to take the prescribed iron.

An absorption of less than $10 \%$ of a $15.0 \mathrm{mg}$. dose of ferrous sulphate in the presence of iron deficiency strongly suggests a diagnosis of coeliac disease,, 3 . whilst a normal or high absorption in a patient with apparently refractory iron deficiency suggests the necessity to look for abnormal blood loss.

\section{Food iron absorption}

Whilst the measurement of the absorption of an inorganic salt of iron can be used as a diagnostic․ㅡ․ test, the measurement of the absorption of iron from various foods is of considerable value in the study of the normal metabolism of iron from the diet. A number of studies have been reported which usew either a biologically labelled food, that is where the radioisotope of iron has been incorporated into theo food by normal biological process, or one labelled in vitro.

Typical methods for the biological labelling of 0 foods are the intravenous administration of ${ }^{59} \mathrm{Fe}$ to $\frac{\mathrm{O}}{\overline{\mathrm{C}}}$ animals to produce labelled haemoglobin, muscle,,$\frac{\Omega}{\Omega}$ 
liver, etc., or chicken to produce labelled eggs, and the growing of cereals and green vegetables in hydroponic tanks where ${ }^{59} \mathrm{Fe}$ is added to the nutrient (Callender, Mallet \& Smith, 1957; McLean-Baird \& Wilson, 1959; Callender \& Warner, 1970; Callender, Marney \& Warner, 1970).

A recent study (Hallberg \& Björn-Rasmussen, 1972) has shown that there is complete isotopic exchange between an added inorganic iron tracer and non-haem iron compounds in a number of foodstuffs when thoroughly mixed with the food during preparation. Thus, the absorption of such a tracer is expected to give a true measurement of the absorption of non-haem iron from the diet. It has also been confirmed by these authors that labelled haemoglobin may be used similarly as a tracer for haem iron absorption from the diet.

In studies with labelled food it has been usual to compare absorption with that from a dose of an inorganic salt. This may be done either by sequential studies using ${ }^{59} \mathrm{Fe}$ alone, or simultaneously by means of independently labelling both forms of iron using ${ }^{55} \mathrm{Fe}$ and ${ }^{59} \mathrm{Fe}$.

Hallberg has preferred the use of the double isotope method both in relating the absorption of a labelled food to that of an inorganic salt of iron and in using the two isotopes to label haem and non-haem foodstuffs (Hallberg \& Björn-Rasmussen, 1970). The total absorption of the two isotopes can be calculated by using a total-body counter to measure the retention of the ${ }^{59} \mathrm{Fe}$ label and by determining the ratio of ${ }^{55} \mathrm{Fe}$ and ${ }^{59} \mathrm{Fe}$ in a blood sample, either by liquid scintillation or gas flow counting.

For the sequential method, a period of some 10-14 days will elapse between the giving of the labelled food iron and the test dose of ferrous sulphate. This may result in a greater spread in the values of absorption than is obtained by the double isotope method, since absorption is related to the state of the iron stores which may change during the period of the study. The use of the multiple dose technique (vide supra) can reduce this variation and this method has for example been used by Callender \& Warner $(1968,1970)$ in studies of the absorption of iron from bread.

In one such study the absorption of two forms of added iron (ferrum redactum and ferric ammonium citrate) was used to test the absorption of iron added to flour as part of the normal procedure of restoring the iron content of high extraction flour to $1.65 \mathrm{mg} /$ $100 \mathrm{~g}$ of flour. The labelled flour was baked into a white loaf and given to a group of iron deficient patients as part of a simple meal. The results of this experiment showed that there was little difference in the value of absorption for either of these two forms of added iron, and that even in the case of quite severe iron deficiency the mean value of absorp- tion was only some $5.0 \%$, against $36.0 \%$ for a standard $5.0 \mathrm{mg}$ test dose of ferrous sulphate given alone. The addition of orange juice to the standard meal resulted in a significant increase in iron absorption from the bread. Nevertheless, it was concluded that the present level of restoration of iron in white bread in Britain is not sufficient to make a significant contribution to the iron balance, even in those subjects whose iron needs are increased.

In a further study the whole body counter was used to investigate ${ }^{59} \mathrm{Fe}$ absorption from bread consumed as part of the normal daily diet. Here the activity of a whole small loaf was measured on the counter and the total retention of activity from the bread was measured 2 weeks after the whole loaf had been eaten, thus allowing an assessment of the contribution of the bread to the iron balance when taken in natural conditions rather than as part of a standard meal.

\section{Iron loss}

Total-body counting techniques for the measurement of iron loss have been reported by a number of workers (for instance, Price, et al., 1964; Heyssel, McKee \& Brill, 1964; Holt et al., 1967; Will \& Boddy, 1967). The test is of particular value in the investigation of the magnitude of blood loss in patients with hypochromic anaemia due to gastrointestinal or excessive menstrual loss (Holt et al., 1968; Holt, Gear \& Warner, 1970; Callender, Warner \& Cope, 1970).

In estimating the loss of ${ }^{59} \mathrm{Fe}$ from the body a number of assumptions have to be made, particularly when this iron loss is to be interpreted as haem iron loss. The principal assumption is that 7-10 days after the administration of an intravenous dose of ${ }^{59} \mathrm{Fe}$ containing approximately $1.0 \mu \mathrm{g}$ of elemental iron, effectively all of that dose will be incorporated into red cells and that any fall in the total-body count due to the ${ }^{59} \mathrm{Fe}$ will, when corrected for physican decay of the isotope, represent loss of blood from the body. Holt et al. (1967) evaluated this technique by studying patients with polycythaemia from whom known quantities of blood was removed by venesection. The mean error for thirty-nine venesections was $-0.2 \%$, range $-22 \%$ to $+25 \%$.

Quantitatively, the interpretation of iron loss into blood loss requires a knowledge of the patient's blood volume. The loss in $\mathrm{ml}=\mathrm{L} / 100 \times \mathrm{BV}$, where $\mathrm{L}=$ percentage loss of total-body radioactivity and $\mathrm{BV}=$ the blood volume in $\mathrm{ml}$.

In such a simple procedure a number of errors are present which must be considered. They are as follows:

(1) The error introduced in the estimation of the patient's blood volume. 
(2) The error due to the iron being incorporated into non-haem compartments.

(3) The bleeding may be of an intermittent nature, the specific activity of the blood will therefore fall in an unknown manner during the period of investigation leading to significant errors, particularly if the loss is at all considerable. Further, in the case of an investigation into blood loss from the upper part of the GI tract, some of the blood lost may be digested and a proportion of the iron reabsorbed.

(4) The counting statistics.

The patient's blood volume may be estimated from tables (Nadler, Hidalgo \& Bloch, 1962) or directly measured by the plasma clearance method using either ${ }^{125}$ I-labelled HSA or the injected dose of ${ }^{59} \mathrm{Fe}$. From the plasma clearance of these isotopes a calculation of the plasma volume can be made and from a knowledge of the PCV, the red cell mass and thus a figure for the total blood volume derived. Dacie \& Lewis (1968) have described these methods in detail.

For the variability due to the percentage of the injected dose actually incorporated into red cells, a correction may be obtained by measuring a blood sample against an accurate standard which is related to the dose injected. This correction is only possible at 7-10 days after dosing.

Effects due to the pattern of loss may be reduced by counting the patient at frequent intervals.

\section{Normal iron loss}

The baseline value of normal iron loss has variously been reported. Some early work using the faecal loss method (Dubach, Moore \& Callender, 1955) gave a value of $0.01 \%$ per day. Finch (1959) using ${ }^{55} \mathrm{Fe}$ levels in blood reported a value of $0.023 \%$ per day. More recent studies using total-body counting techniques have given values of iron loss following oral administration of $0.136 \%$ per day (Price et al., 1962), $0.24 \%$ per day (Reizenstein \& Brann, 1965), 0.15\% per day (Will \& Boddy, 1967).

Figures for loss following intravenous dosing have varied from those of Saito et al. (1964) who report a figure of $0.03 \%$ per day, to values obtained by McKee et al. (1965) and Heinrich (1970) who found 0.097 and $0.136 \%$ per day respectively.

The variability of the values derived from totalbody counter studies and the high rate of loss reported by a number of workers has been a matter of importance. For a normal man containing $55 \mathrm{mg} \mathrm{Fe} /$ $\mathrm{kg}$ body weight, an absorption of about $1 \mathrm{mg} /$ day of iron is required for normal iron balance. This figure would allow a loss of only $0.03 \%$ per day.

Heinrich (1970) in a more recent study has pointed to the level of impurities in the commercially available ${ }^{59} \mathrm{Fe}$, particularly ${ }^{60} \mathrm{Co}$, as being responsible for some of the high values of iron loss reported. Le
Blanc \& Johnson (1972) have confirmed this conڤ tamination in six samples of ${ }^{59} \mathrm{Fe}$ from three differen $\mathrm{E}$ suppliers of this radiopharmaceutical. Although the initial level of this contamination may be low, due t $\theta$. the very much longer half-life of ${ }^{60} \mathrm{Co}(5 \cdot 2$ years) the: impurities can be of the order of $10 \%$ after three of more half-lives of the ${ }^{59} \mathrm{Fe}$. A further problem is the almost identical gamma spectrum of these two radio nuclides, so that separation by means of pulse height analysis is not possible.

In physiological terms, this situation can producE an erroneously high loss of radioactivity from the body due to the very different metabolism of iron and cobalt, significant quantities of cobalt bein $\overrightarrow{\mathrm{gu}^{\circ}}$ excreted in the urine against negligible amounts of iron (Valberg, Ludwig \& Olatunbosun, 1969).

Following purification of the ${ }^{59} \mathrm{Fe}$ to very hig? standards (99.999\%), Heinrich (1970) has givere values of loss of $0.032 \pm 0.012 \%$ per day for malesi $0.05 \pm 0.008 \%$ per day for menstruating femaleş and $0.038 \pm 0.018 \%$ per day for non-menstruating females.

The purification of the ${ }^{59} \mathrm{Fe}$ has also allowed a용 accurate determination of the physical half-life $\left(t \frac{1}{2}\right)_{\vec{e}}$ which is given as 44.52 days. Previously reportee values of this parameter have ranged from $44 \cdot 3$ to $45 \cdot 1$ days, and any inaccuracy for this value can atse lead to an inaccurate assessment of the amountoos iron lost.

\section{The counting statistics}

The imprecision due to the counting statisticy arises largely due to the basic counting technique employed. In the test for iron loss, it is a smalt change in the retained activity that is being measured? this means that small losses are within the statistical variation of the observed counts.

For a simple shadow shield counter using two 4 in diameter $\times 3$ in thick $\mathrm{NaI}$ (TL) detectors, a dose to the patient of $4.0 \mu \mathrm{Ci}$ will give a precision equat to twice the standard error of the retention value? which is equivalent to $170 \mathrm{ml}$ of blood (total bloog volume taken as 51 ) (Warner, 1968). Depending upo the period of time over which measurements are made, the precision is not markedly improved by increasing the administered dose or by increasing the efficiency of the counter. Heinrich (1970) with the $4 \pi$ counter only achieved a precision of about $100 \mathrm{~m} \Phi$ if his published figures are correctly interpreted as being expressed as standard deviations rather that coefficients of variation.

Taking an overall view of this technique, the limitas tions are such that the precise measurement of sma年 amounts of iron loss over short periods of time arê not possible. However, it can provide an extremelyt useful clinical indication of whether loss of iron fron the body is contributing to a hypochromic anaemia 


\section{Some clinical applications}

Three cases reported by Holt et al. (1967) are particularly good examples of the clinical usefulness of the measurement of iron loss.

The first patient had recurrent iron deficiency anaemia. Her iron absorption was normal and her anaemia was thought probably to be due to menorrhagia. The magnitude of the bleeding was, however, not fully appreciated until a blood loss study showed a loss of $870 \mathrm{ml}$ during a single menstrual period. Hysterectomy was performed, and thereafter there was no significant fall in total-body ${ }^{59} \mathrm{Fe}$ (Fig. 4), confirming that menorrhagia was the sole cause of her anaemia.

The second patient was an 18-year-old boy who complained of increasing shortness of breath and cough with haemoptysis. He was found to have a severe hypochromic anaemia, and a chest radiograph showed diffuse opacities in both lower lobes. Fig. 5 shows that the total-body count due to the ${ }^{59} \mathrm{Fe}$ remained constant despite a fall in haemoglobin, indicating that external blood loss was not the cause of the anaemia. Later, iron-containing macrophages were found in the sputum and a diagnosis of idiopathic pulmonary haemosiderosis was made. Although blood was being lost from circulation, it was being sequestered in the lung, thereby explaining why the total-body count did not fall.

The third patient was a 53-year-old man with ankylosing spondylitis who had a recurrent iron deficiency anaemia for 12 years. During the period of study he had been taking analgesics to control pain, and it seems likely that gastrointestinal blood

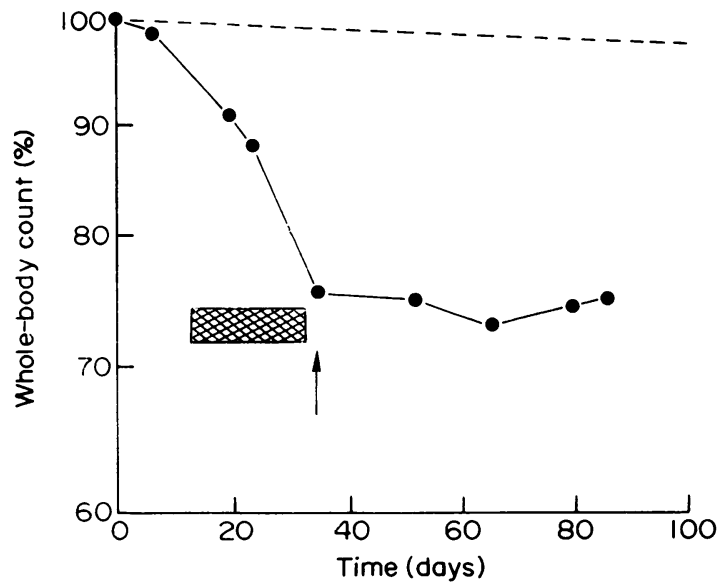

Fig. 4. Blood loss for a patient with menorrhagia. Blood loss during first 35 days $=870 \mathrm{ml}$; overall blood loss (91 days) $=940 \mathrm{ml}$, absorption $=33 \%$. The arrow indicates hysterectomy and the hatched area a menstrual period. - - - , control graph (approx. $0.03 \%$ per day) (Holt et al., 1967). loss, which amounted to 1.21 in 105 days (Fig. 6) was related to this medication.

The use of a total-body counter to measure blood loss in menorrhagia in a series of sixteen patients has also been reported (Callender et al., 1970). Here, the effect of an antifibrinolytic agent (tranexamic acid) on excessive blood loss was investigated. This double blind study involved the use of a placebo as well as a 'before treatment' series of loss measurements. Each patient was measured over three menstrual periods for each of the three regimes: no treatment, placebo and tranexamic acid treatment.

The results of this study showed that there was no significant difference between the mean loss for 'no treatment' and placebo, and that the tranexamic

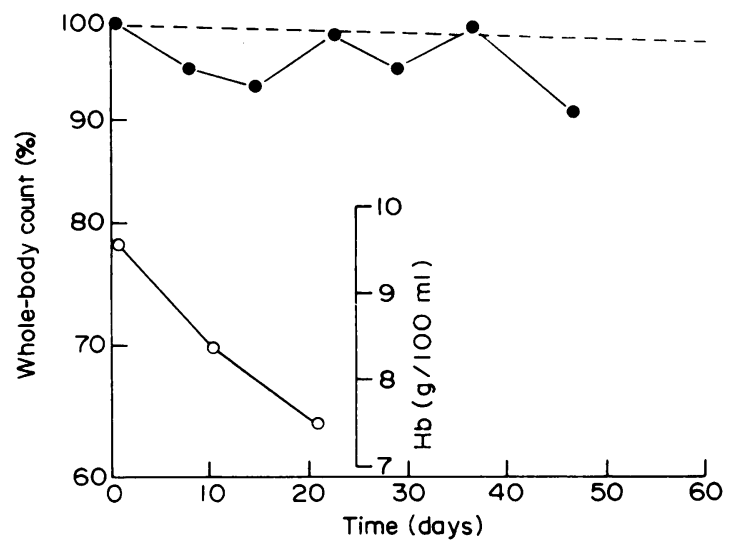

FIG. 5. Blood loss for a patient with idiopathic pulmonary haemosiderosis. Despite a fall in haemoglobin, the total body count showed that no significant quantity of blood was lost during the period of the investigation. Absorption $=25 \%$. - - - control graph (approx. $0.03 \%$ per day) (Holt et al., 1967).

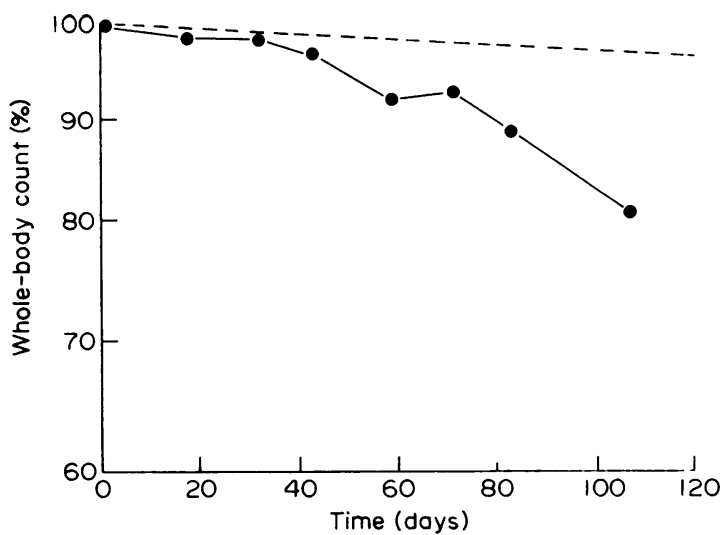

Fig. 6. Blood loss for a patient with ankylosing spondylitis who was taking analgesics to control pain. Blood loss over 105 days $=1200 \mathrm{ml}$, absorption $=29 \%$ - - - control graph (approx. $0.03 \%$ per day) (Holt et al., 1967). 


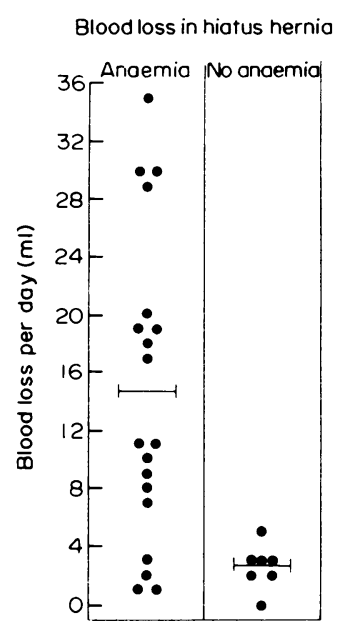

Iron absorption in hiotus hernio

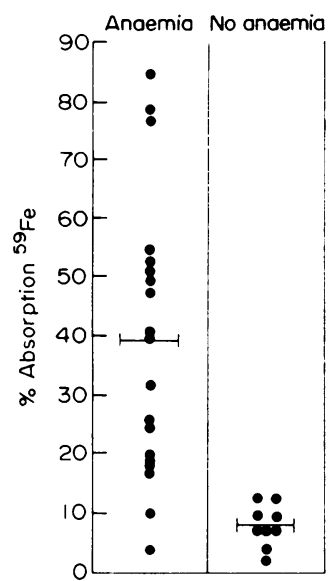

FIG. 7. Blood loss and iron absorption in hiatus hernia in relation to anaemia. The anaemic group show an increased iron absorption and a mean blood loss of $15 \mathrm{ml} /$ day; the non-anaemic group have a normal absorption and minimal evidence of blood loss (Holt et al., 1968).

acid had a significant effect in reducing the value of mean loss.

This measurement technique has also been used to advantage to study the mechanism of iron deficiency in hiatus hernia (Holt et al., 1970). Fig. 7 shows the blood loss and iron absorption for patients with hiatus hernia in relation to anaemia. The anaemic group showed an increased iron absorption and a mean blood loss of $15 \mathrm{ml} /$ day; the non-anaemic group had a normal absorption and minimal evidence of blood loss.

\section{Animal studies}

Studies on iron metabolism in laboratory animals can also be performed using the same apparatus as that for the human studies. The principal advantage is that a group of animals can be counted all together and a mean absorption obtained directly for the whole group. A study of iron absorption in the rat measured both as a group and as individual animals showed good agreement between the two methods (Faggioni, Warner \& Callender, 1972).

\section{References}

Anderson, E.C., Schuch, R.L., Perrings, J.D. \& Langham, W.H. (1956) The Los Alamos human counter. Nucleonics, $14,1$.

ANDERSON, J.A. \& WARNer, G.T. (1970) Estimation of the standard error of retention in whole-body counter studies and its relevance to counter design. Physics in Medicine And Biology, 15, 281.

Badenoch, J.D. \& Callender, S.T. (1954) Iron metabolism in steatorrhea. The use of radioactive iron in studies of absorption and utilization. Blood, 9, 123.
BARNABY, C.F. \& SMiTh, T. (1971) Calibration of a wholêbody counter suitable for use in routine clinical investigs tions. Physics in Medicine and Biology, 16, 97.

BoDDY, K. (1967) The development and performance of prototype shadow shield body monitor. Physics in Medicine and Biology, 12, 43.

Booth, C.C. \& Mollin, D.L. (1956) Plasma, tissue and uriñ ary radioactivity after oral administration of ${ }^{56} \mathrm{Co}$ labelled vitamin $\mathrm{B}_{12}$. British Journal of Haematology, 2, 223.

BURCH, P.R.J. \& SPIERS, F.W. (1953) Measurement of $\gamma$-radia tion from the human body. Nature, 172, 519.

CAllender, S.T.C. (1962) Iron metabolism using iron 59 as a tracer. Proceedings of the Royal Society of Medicine, 5 145 .

Callender, S.T., Mallett, B.J. \& Smith, M.D. (195 $\overrightarrow{\mathrm{T}}$ Absorption of haemoglobin iron. British Journal of Haematology, 3, 186.

Callender, S.T., Marney, S. JR \& Warner, G.T. (197 Eggs and iron absorption. British Journal of Haematolog 9 $19,657$.

Callender, S.T. \& Warner, G.T. (1968) Iron absorption from bread. American Journal of Clinical Nutrition, $2 \mathrm{f}$ 1170.

Callender, S.T. \& WARner, G.T. (1970) Iron absorptiofi from brown bread. Lancet, 1, 546.

Callender, S.T. \& Warner, G.T. (1971) Absorption of 'slow $\mathrm{Fe}^{\prime}$ measured with a total-body counter. Currers Therapeutic Research, 13, 591.

Callender, S.T., Warner, G.T. \& Cope, E. (1970) Treatment of menorrhagia with tranexamic acid: a double bline trial. British Medical Journal, 4, 214.

Callender, S.T., Witts, L.J., Warner, G.T. \& Oliver RRe (1966) The use of a simple whole-body counter for haepiow tological investigations. British Journal of Haematoly 12, 276.

Christian, J.E., Kessler, W.V. \& Ziemer, P.L. (1962) A2 liquid scintillation counter for determining the radio activity of large samples including man and animalo International Journal of Applied Radiation and Isotope. 13, 557.

Clapham, W.F. \& Hayter, C.J. (1962) The measurement gamma-emitting isotopes in faeces. Physics in Medicine an\& Biology, 7, 313.

Compton, A.H. (1923) A quantum theory of the scatterin of X-rays by light elements. Physics Review, 21, 483.

Cook, J.D., Palmer, H.E., Pailthorpe, K.G. \& Fincho C.A. (1970) The measurement of iron absorption by whole body counting. Physics in Medicine and Biology, 15, 46\%

COOK, J.D. \& VALBERG, L.S. (1963) Evaluation and use of large plastic scintillator. Journal of Laboratory and Clinicadh Medicine, 61, 317.

DACIE, J.V. \& Lewis, S.M. (1968) Practical Haematology, 4th edn., p. 354. Churchill, London.

DERN, R.J. \& HART, W.L. (1961) Studies of iron from blood samples, and preparation of ferrous perchlorate for liquiscintillation counting. Journal of Laboratory and Clinicat Medicine, 57, 460.

Dubach, R., Callender, S.T.C. \& Moore, C.V. (1948) Studies in iron transportation and metabolism. VIN Absorption of radioactive iron in patients with fever and with anaemias of varied etiology. Blood, 3, 526.

Dubach, R., Moore, C.V. \& Callender, S.T. (1955) Studies of iron transport and metabolism. IX. The excretion of iron measured by isotope technique. Journal of Laborator $x \bar{D}$ and Clinical Medicine, 45, 599.

DuDleY, R.A. (1970) Radioaktive isotope in klinik und forschung. In: Vorträge am Gasteiner Internationale Symposion, 1970, p. 135. Urban \& Schwarzenberg München. 
Dymock, I.W., Godfrey, B.E. \& Williams, R. (1971) A comparison of methods for the determination of iron absorption using a whole-body counter. Physics in Medicine and Biology, 16, 269.

EAKINS, J.D. \& BROWN, D.A. (1965) The simultaneous determination of iron-55 and iron-59 in blood by liquid scintillation counting. U.K.A.E.A. Research Report, A.E.R.E. R4945.

Faggioni, L.G. Warner, G.T. \& Callender, S.T. (1972) In preparation.

FINCH, C.A. (1959) Body iron exchange in man. Journal of Clinical Investigation, 38, 392.

Francois, P.E. \& SzUR, L. (1958) Use of iron-52 as a radioactive tracer. Nature, $182,1665$.

Glass, H.I., Clarkson, D.G. \& Burns, H.G. (1964) A whole-body counter for clinical application. Physics in Medicine and Biology, 9, 57.

HAllberG, L. \& BJörn-RASmussen, E. (1972) A new two pool model using two radio-iron isotopes given as haem and non-haem iron. Scandinavian Journal of Haematology, 9, 193.

Hallberg, L. \& Brise, H. (1960) Determination of $\mathrm{Fe}^{55}$ and $\mathrm{Fe}^{50}$ in blood. International Journal of Applied Radiation and Isotopes, 9, 100.

HallberG, L., Sölvell, L. \& BRise, H. (1958) A new method for studies on iron absorption in man. VIIth International Congress of the Society of Haematology, Rome.

Haln, P.F., Bale, W.F., Lawrence, E.O. \& Whipple, G.H. (1939) Radioactive iron and its metabolism in anaemia. Journal of Experimental Medicine, 69, 739.

HeINRICH, H.C. (1970) Iron deficiency. In Colloquia Geigy, p. 213. Academic Press, London.

Heyssel, R.M., MCKee, L.C. \& Brill, A.B. (1964) The measurement of iron excretion using the whole-body counter. Proceedings of the Symposium on Nutrition, St Louis, Massachusetts.

Holt, J.M., Gear, M.W.L. \& Warner, G.T. (1970) The role of chronic blood loss in the pathogenesis of postgastrectomy iron-deficiency anaemia. Gut, 11, 847.

Holt, J.M., Mayet, F.G.H., Warner, G.T. \& Callender, S.T. (1967) Measurement of blood loss by means of a whole-body counter. British Medical Journal, 4, 86.

Holt, J.M., Mayet, F.G.H., Warner, G.T., Callender, S.T. \& GUNNING, A. (1968) Iron absorption and blood loss in patients with hiatus hernia. British Medical Journal, 3, 22.

JENNER, H. \& ÖBRINK, K.J. (1962) Determination of $\mathrm{Fe}^{55}$ and $\mathrm{Fe}^{50}$ mixtures in blood by liquid scintillation counting. Scandinavian Journal of Clinical and Laboratory Investigation, 14, 466.

JOSEPHS, H.W. (1958) Absorption of iron as a problem in human physiology: a critical review. Blood, 13, 1.

Le Blanc, A.D. \& Johnson, P.C. (1972) ${ }^{60}$ Co a constant contaminant of pharmaceutically prepared ${ }^{50} \mathrm{Fe}$. Physics in Medicine and Biology, 17, 418.

LiNDELl, B. (1962) An 'open-booth' body counter. In: Symposium on Whole Body Counting, p. 234, International Atomic Energy Agency, Vienna, June 1961.

LOEvinger, R. \& Berman, M. (1951) Efficiency criteria in radioactive counting. Nucleonics, 9, 26.

MCKeE, I.C., King, J.A., Hagman, R.C. \& Heyssel, R.M. (1965) Studies of human iron metabolism with a wholebody counter. In: Radioactivity in Man, p. 402. C. C. Thomas, Springfield, Ill.

MCLean-Baird, I. \& Wilson, G.M. (1959) The pathogenesis of anaemia after partial gastrectomy. II. Iron absorption after partial gastrectomy. Quarterly Journal of Medicine, 28, 35.

Kendall, M.G. \& Stuart, A. (1958) The Advanced Theory of Statistics, vol. 1, p. 23. Griffin, London.
Miller, C.E. (1962) An experimental evaluation of multiplecrystal arrays and single-crystal techniques. In: Symposium on Whole Body Counting, p. 81, International Atomic Energy Agency, Vienna, June 1961.

Nadler, S.B., Hidalgo, J.V. \& Bloch, T. (1962) Prediction of blood volume in normal human adults. Surgery, 51, 224.

Oliver, R. (1953) The use of a scintillation gamma counter for the estimation of iodine-131 in liquid samples. British Journal of Radiology, 26, 663.

Oliver, R. \& WARNER, G.T. (1966) Some factors affecting the uniformity of response in whole-body counters. British Journal of Radiology, 39, 554.

Paix, D., Davis, A.E. \& Blagonravoff, L. (1965) The radioactive assay of bulky samples. Journal of the College of Radiologists of Australia, 9, 268.

Palmer, H.E., CoOK, J.D., Pailthorpe, K.G. \& Finch, C.A. (1970) A whole-body counter for precision in vivo measurement of radio-iron. Physics in Medicine and Biology, 15, 457.

Peacock, W.C., Evans, R.D., Irvine, J.W., Good, W.M. KipP, A.F., Weiss, S. \& GibBson, J.G. (1946) The use of two radioactive isotopes of iron in tracer studies of erythrocytes. Journal of Clinical Investigation, 25, 605.

Perry, S.W. \& WARner, G.T. (1963) A method of sample preparation for the estimation of ${ }^{55} \mathrm{Fe}$ in whole blood by the liquid scintillation technique. International Journal of Applied Radiation and Isotopes, 14, 397.

Pircher, F.J., Horn, E.G., Reeves, R.J. \& Buffalo, T. (1965) Design and properties of the whole-body scanner at Duke. Journal of Nuclear Medicine, 6, 389.

Price, D.C., CoHN, S.H. Wasserman, L.R., Reizenstein, P.G. \& Cronkite, E.P. (1962) The determination of iron absorption and loss by whole-body counting. Blood, 20 , 517.

PrICE, D.C., Forsyth, E.M., Cohn, S.H. \& Cronkite, E.P. (1964) The study of menstrual and other blood loss, and consequent iron deficiency, by $\mathrm{Fe}^{58}$ whole-body counting. Canadian Medical Association Journal, 90, 51.

Reizenstein, P.G. and BranN, I. (1965) Normal and pathological radio-iron excretion in man. In: Radioactivity in Man, p. 391. C. C. Thomas, Springfield, Ill.

Roesch, W.C. \& Palmer, H.E. (1963) Research and development activities in radiological sciences. U.S.A.E.C.Report HW-70050.

RuNDo, J. (1958) Body radioactivity measurement as an aid in assessing contamination by radionuclides. Proceedings of the 2nd U.N. International Conference, 23, 101.

Saito, H., Sargent, T. Parker, H.G. \& Lawrence, J.H. (1964) Whole-body iron loss in normal man measured with a gamma spectrometer. Journal of Nuclear Medicine, 5, 571 .

Schiffer, L.M., Price, D.C., Cuttner, J., Cohn, S.H. \& CRONKITE, E.P. (1964) A note concerning the ' 100 per cent value' in iron absorption studies by whole-body counting. Blood, 23, 757.

Smith, M.D. \& Malletr, B.J. (1957) Iron absorption before and after partial gastrectomy. Clinical Science, 16, 23.

TAPPIN, J.W. (1963) The conversion of a small laboratory into a low background room suitable for counting whole-body radiation. British Journal of Radiology, 36, 608.

Tothill, P. \& Galt, J.M. (1971) Quantitative profile scanning for the measurement of organ radioactivity. Physics in Medicine and Biology, 16, 625.

Trott, N.G., Parnell, C.J., Hodt, H.J. \& Entwistle, R.F. (1963) Studies in the design and application of a clinical low background counting room. British Journal of Radiology, 36, 592.

ValberG, L.S., Ludwig, J. \& Olatunboson, D. (1969) Alterations in cobalt absorption in patients with disorders of iron metabolism. Gastroenterology, 56, 241. 
WARNer, G.T. (1968) The design, development and application of a total-body counter for clinical applications. D.Phil. Thesis, Oxford University.

Warner, G.T. \& Oliver, R. (1962) A plastic phosphor well counter for sample volumes up to $400 \mathrm{ml}$. British Journal of Radiology, 35, 413 .
WARner, G.T. \& Oliver, R. (1966) A whole-body counter for clinical measurements utilizing the 'shadow shield' technique. Physics in Medicine and Biology, 11, 83.

WILL, G. \& Boddy, K. (1967) Iron turnover estimated by a $\subseteq$ whole-body monitor. Scottish Medical Journal, 12, 157. 